\title{
REFLEXÕES SOBRE O PARADIGMA MILITANTE EM UMA ESCOLA DE EDUCAÇÃO DE JOVENS E ADULTOS
}

\author{
REFLECTIONS ABOUT THE MILITANT PARADIGM IN A SCHOOL OF YOUTH AND ADULT \\ LITERACY EDUCATION
}

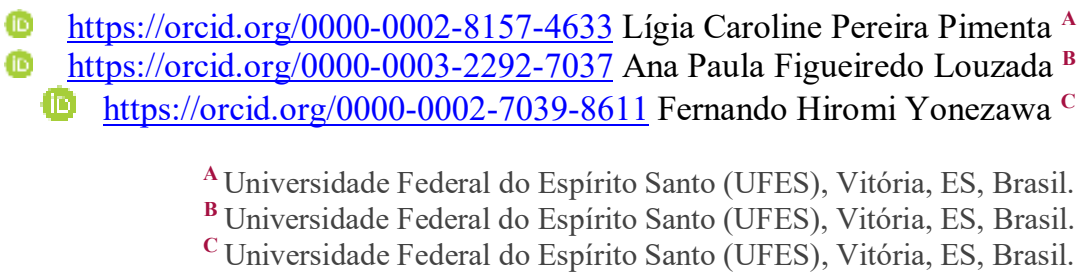

Recebido em: 17 ago. 2020 | Aceito em: 20 ago. 2021 Correspondência: Ligia Pimenta (ligiapimenta@gmail.com)

\section{Resumo}

Este artigo é fruto de pesquisa qualitativa de mestrado em Psicologia Institucional e teve como campo de intervenção uma escola municipal de modalidade Educação de Jovens e Adultos, na cidade de Vitória, estado do Espírito Santo. Fez parte também de um conjunto integrados de pesquisas realizadas na mesma EMEF. O objetivo geral foi analisar como os educadores participantes estabeleciam conexões com o paradigma militante presente no cotidiano de trabalho na escola. O método utilizado foi o cartográfico e a metodologia se deu por levantamento bibliográfico, utilização de diário de campo, entrevistas e gravações de áudio. $\mathrm{O}$ material produzido subsidiou a realização das entrevistas semiestruturadas, além da qualificação de informações coletadas acerca da militância. Para resguardar o sigilo, tanto a escola quanto os participantes não foram identificados. Concluímos que a urgência por outros modos militantes foi demonstrada naquela escola através de um plano ético de subjetivação, cuja existência foi demonstrada em ações micropolíticas que constituíram no plano hermenêutico o seu êthos, conforme a teoria foucaultiana.

Palavras-chave: Psicologia institucional; Militância; Educação; Êthos.

\begin{abstract}
This article is the result of a master's research in Institutional Psychology and its intervention field was a municipal school of youth and adult literacy education, in the city of Vitória, state of Espírito Santo. The objective was to analyze how educators established connections with the militant paradigm present in daily work at school. The methodology was based on a bibliographic research, the use of a field diary and audio recordings. The material produced supported the realization of semi-structured interviews, in addition to the qualification of information collected about militancy. To protect confidentiality, both the school and the participating educators were not identified. We conclude that the urgency for other militant modes is presented in that school through an ethical plan of subjectivation, whose existence was demonstrated in micropolitical actions that constituted an ethos.
\end{abstract}

Keywords: Institutional psychology; Militancy; Education; Ethos. 


\section{Introdução}

Este artigo é fruto de pesquisa qualitativa oriunda de dissertação de mestrado em Psicologia Institucional. A pesquisa, descrita em parte nesta publicação, ocorreu entre os anos de 2015 e 2017 e teve como campo de investigação uma escola municipal de ensino fundamental - modalidade Educação de Jovens e Adultos (EMEF EJA), localizada na cidade de Vitória - Espírito Santo. Visando garantir o compromisso de sigilo de nomes feito com instituição, a escola não será identificada neste artigo.

Essa escola foi criada como resultado de um projeto de extensão do Centro de Educação da Universidade Federal do Espírito Santo em parceria com a Prefeitura Municipal de Vitória e tinha como objetivo a implementação de projetos de alfabetização para servidores municipais. Parte dos educadores que integravam o quadro docente da EMEF EJA durante a pesquisa fez parte do projeto de extensão do qual ela se originou. É a única escola na cidade a qual é garantida a ação da metodologia de ensino pautada em Paulo Freire. Além disso, procura promover eventos que envolvem o entorno escolar, e se utiliza de temas geradores para trabalhar a alfabetização crítica, bem como o letramento de seus estudantes.

Para além das atividades escolares, a rotina de trabalho está quase sempre permeada de situações urgentes com as quais os professores se mobilizam para lidar. São algumas delas: estudantes que não conseguem mais frequentar as aulas porque não têm condições financeiras para o deslocamento; conflitos territoriais devido à influência do tráfico; estudantes com transtornos mentais não identificados etc. Por essa e outras características, a escola é conhecida na rede de ensino municipal como um lugar de professores militantes. Ao longo da pesquisa identificou-se que aos personagens que não se encaixavam na rotina ou não acolhiam as pautas da EMEF EJA a solução encontrada era o remanejamento. Apesar disso, o grupo de educadores participantes da pesquisa denotou não compreender a militância como algo que direcionava seu trabalho.

Assim, utilizamos situações-problema que emergiram no processo de pesquisa para disparar reflexões com os participantes acerca das conexões existentes entre sua atividade e algumas práticas militantes. O intuito da pesquisa foi identificar e problematizar como a equipe da escola lidava com os modos militantes nela presentes.

Vislumbramos com a pesquisa produzir uma prática afirmativa em educação, e procuramos com ela evidenciar uma dimensão diferente da militância, que não carece de institucionalização para existir. Referimo-nos ao plano hermenêutico da militância, conjugado entre o que Foucault (2011) denominou um êthos e as ações dos educadores da EMEF EJA. Este êthos não é único ou exclusivo de um grupo, tem caráter micropolítico e pode ser 
encontrado quando, por exemplo, por meio da atuação docente se provoca desvios nos paradigmas hegemônicos presentificados na educação.

No decorrer da pesquisa encontramos pistas de como transformações ocorridas nos exercícios militantes produziram nos docentes da EMEF EJA determinadas posturas diante de questões que emergiam em seu trabalho. Nessa perspectiva, este artigo apresenta algumas pistas que, historicamente, falam sobre práticas de militância. Através destas pistas delineamos a constituição do sujeito da militância, suas vanguardas e as variações em ativismo, e exemplificamos sua reprodução no cotidiano da escola.

Começaremos com o militantismo ou a "militância-vanguarda" (SCHUBERT, 2014, p. 94), do qual tratamos de cartografar parte de suas modulações, dadas ao longo da história das mobilizações sociais no século XX. Seguiremos com análises sobre o ativismo, elucidando sua importância para a militância na contemporaneidade. Por fim, buscamos criar com nossas ferramentarias outros usos para a militância no contemporâneo daquele espaço escolar.

\section{Metodologia}

A escolha do método cartográfico como referência para a realização da pesquisa se deu por esta sustentar a aposta de que a relação entre campo e pesquisador é indissociável. Ao mesmo tempo que exige flexibilidade do pesquisador no manejo metodológico, uma vez que o campo, enquanto espaço que reflete aspectos cognitivos e afetivos do grupo, pode sofrer alterações na medida em que a pesquisa avança (KASTRUP, 2012; PASSOS; BARROS, 2012).

Para subsidiar as intervenções realizadas, foram utilizadas gravações de áudio captadas durante as formações continuadas dos educadores, com devido aval dos participantes, além de registros dos diários de campo. Procedeu-se, ainda, um levantamento bibliográfico que demonstrou a existência de dois grandes focos de investigação acadêmica sobre as militâncias em voga: o primeiro vinculado a uma explicitação das militâncias partidárias no Brasil (história e ação dos militantes na fundação e consolidação em partidos), e o segundo vinculado ao exercício da militância na consolidação de leis. Este artigo não se concentrará na militância partidária ou mesmo vinculada à produção de legislações (o que não nos assegura de nos confrontar com essas perspectivas neste trabalho). O levantamento se fundamentou em produções acadêmicas que abarcaram, por exemplo, o conceito de militância como um conjunto de ações sociais que compreendem a manifestação de um comportamento coletivo (MACHADO, 2007). 
De posse do conteúdo produzido nas entrevistas e gravações, e da bibliografia levantada, traçamos um relevo histórico-político-afetivo, por meio do qual foram identificadas pistas que demonstravam a existência de um paradigma militante na metodologia de ensino defendida pela escola. Segundo Kastrup (2012), estabelecer pistas auxilia o pesquisador a coletivizar a experiência da investigação, possibilitando a tarefa de produzir análises de elementos de cunho afetivo e político. Nesta perspectiva, pistas não existem tão somente para levarem umas às outras, mas antes para aguçar o olhar do pesquisador-cartógrafo, de modo que este se atente ao modo como as conexões entre elas se formaram. Para Lemos e Oliveira $(2017$, p.45)

Não só de mapas e geografia é construída a cartografia. Apesar de ser sua origem, e mais comumente relacionada a esse aspecto, a cartografia também pode ser entendida como método de pesquisa, auxiliando o pesquisador a traçar seu caminho enquanto apreende e é apreendido pelas circunstâncias.

Assim, buscamos criar condições para que este mapeamento fosse pano de fundo para intervenções junto aos educadores. Utilizamos os horários de planejamento, de aula e de formação continuada para inserir debates acerca de processos sócio-históricos descritos na história da militância. O delinear sócio-histórico da militância nos auxiliou no processo de análise, inclusive na produção de questões-problemas, como: que modos as ações de enfrentamento político vividas por alguns professores nas décadas de 1980 e 1990 se presentificavam em seu trabalho na escola? Em quais espaços são legitimadas as demonstrações dessas militâncias? E, ainda, dentro da proposta metodológica da escola, de que modos as militâncias contribuem para a formação crítica dos estudantes?

Para subsidiar as análises, serão apresentadas falas de educadores participantes da pesquisa, as quais foram coletadas durante as formações continuadas. Estes educadores serão referenciados por números.

\section{O paradigma da militância na EMEF EJA}

Investigar conhecimentos teóricos acerca dos modos militantia (SCHUBERT, 2014) fez-se importante para a pesquisa, e este um exercício, além contextualizar as transformações ocorridas, também nos ajudou a pensar como tais mudanças produziram compreensões binárias sobre a militância no cotidiano. No decorrer da pesquisa não foi incomum que ocorressem situações que explicitassem a existência de um paradigma militante na escola.

Militância... Eu penso... Eu não levanto bandeira, eu não tenho bandeira. Assim, a escola tem muitas bandeiras... Eu adiro às bandeiras da escola. Não são minhas bandeiras pessoais. A bandeira LGBT, a bandeira de africanidades, não são minhas bandeiras pessoais. [...] Então, assim, não são minhas bandeiras. Mas, para mim, o que me cabe de militância na EMEF EJA é sair um pouco daquele professor profissional e ser uma coisa mais humanizada, ser mais humana. Deixar de ser 
professor e aluno, eu penso né, e ser dois seres humanos ali, duas pessoas. Claro que a gente tem aquela obrigação, né, de passar o conhecimento. Mas eu penso que aqui a gente está um pouco pensando no social (Educador 1).

Mas o que, de fato, um paradigma operacionaliza? A que nos referimos quando afirmamos a existência de um paradigma militante no contexto de uma escola de Educação de Jovens e Adultos? Segundo Neves da Silva (2008, p. 40),

podemos dizer que todo paradigma refere-se a uma determinada estratégia de produção de conhecimento, socialmente compartilhada, na qual se atualizam: uma dimensão epistemológica (como conhecemos), uma dimensão ontológica (o que é isso a ser conhecido), uma dimensão metodológica (que ferramentas utilizamos nesta investigação) e uma dimensão ética (que valores conduzem nossas estratégias de produção do conhecimento).

Para Guareschi (2008), paradigmas constituem-se a partir da criação de problemas e, por conseguinte, das condições para sua resolução. Assim sendo, eles tratam das referências direcionadoras para a realização de uma atividade, que estão localizados num determinado contexto sociocultural. Ele "nos traz possibilidades de entendermos as formas e mecanismos que as pessoas utilizam para se inserir no mundo, estar no mundo ou de pensar e significar suas práticas ou a si próprias nele” (GUARESCHI, 2008, p. 8).

Neves da Silva (2008) afirma que isso ocorre porque, mais que uma estratégia de produção de conhecimento, um paradigma atualiza formas de valorização da própria experiência subjetiva. É importante salientar que a existência de outras roupagens paradigmáticas nem sempre significa a invalidação e/ou extinção de um modelo anterior. Analisamos que a existência desses conjuntos de normas denota uma multiplicidade de alternativas para se lidar com fenômenos diversos. Portanto, modelos, normas, regras, enfim, paradigmas são mutáveis; e, mesmo assumindo a mutabilidade, estes modelos contêm uma natureza contraditória: cria-se um padrão (uma norma) que, para acompanhar as variações do ambiente, precisa ser capaz de variar.

Logo, ao nos referirmos a um paradigma militante, estamos tratando de modos permeados por contraditoriedades próprias, que disparam e conduzem as ações de militância e que sofrem alterações em meio à dinâmica social. Ainda com Neves da Silva (2008), faz-se imprescindível "mostrar o quanto os processos de subjetivação expressam determinados valores e que estes valores orientam nossos modos de existência e nossas estratégias de produção de conhecimento" (NEVES DA SILVA, 2008, p. 41). Por esta razão, afirmamos que o paradigma militante atravessa sujeitos, mas não se aloca, nem mesmo se faz propriedade deles. Vejamos:

[...] ao falarmos de ética e paradigmas não estamos querendo estabelecer uma relação artificial entre dois termos distintos, mas sublinhar a relação de complementaridade e de pressuposição recíproca entre ambos. Não temos de um lado a ética e de outro um 
conjunto de paradigmas. Temos, isto sim, determinadas estratégias de produção de conhecimento (paradigmas) que expressam determinados valores que orientam nossos modos de existência (ética)" (Ibidem, p. 42).

$\mathrm{Na}$ escola, o paradigma militante quase sempre se apresentava na forma de analisadores (ARDOINO \& LOURAU, 2003), ou seja, acontecimentos ou fenômenos que atravessam a dinâmica institucional portando os coeficientes de análises ('não-ditos'). Isto ocorria principalmente quando precisávamos desenvolver atividades de suma importância para a manutenção da escola enquanto um espaço democrático de aprendizagem e produção de conhecimento. As reuniões de gestão, ocorridas majoritariamente nas segundas-feiras, foram espaços em que esses elementos foram mais preponderantes.

Com a iminência da troca da gestão municipal após as eleições de outubro de 2016, por exemplo, a escola precisou urgentemente avaliar e traçar estratégias para manter suas salas de aula dentro dos equipamentos públicos para não perder espaços tão importantes na cidade. Durante uma reunião, recebemos a notícia de que um abrigo para população em situação de rua com necessidades especiais entrou em contato com a equipe gestora solicitando 15 vagas para seus usuários. A princípio, mapeamos em quais espaços poderíamos alocar esses estudantes para garantir que todos fossem matriculados na escola, quando um dos coordenadores se posicionou contrário aos encaixes afirmando que a escola precisava urgentemente largar o hábito do jeitinho brasileiro e assumir de fato a militância que alegava defender (sic). Situação semelhante ocorria quando o assunto estava relacionado às transferências de estudantes em idade regular para a escola [principalmente em se tratando daqueles em cumprimento de Medidas Socioeducativas] amparados no discurso do acolhimento às diversidades. Essa situação se configurou como analisadora porque deu visibilidade a instabilidade de alguns posicionamentos adotados pela escola e nos conduziu à realização da análise.

Acolher a este tipo de demanda requer um esforço que diz respeito não só à oferta de vagas, como também à logística dos espaços em que estudantes são acolhidos (devido aos conflitos de território muitas vezes provenientes do envolvimento de alguns destes sujeitos com o tráfico) e a reação de parte dos educadores - que lidam de forma arredia/desconfiada com a presença destes estudantes. Assim, ao mesmo tempo em que a escola se propunha inclusiva e buscava garantir o direito ao acesso e permanência no processo de escolarização, também lidava com questões que por vezes ultrapassavam sua capacidade de resolução. A escola se via diante do risco de acolher a qualquer custo ao que os docentes leem como um refugo do sistema educacional e os professores demarcaram a necessidade de exigir que o sistema educacional não mais atribua a estes estudantes o predicativo de sujeitos indesejáveis (sic). 
Militância seria o engajamento coletivo numa direção. Eu leio dessa forma, né. Cada um com seu conceito, mas com sua visão pessoal sobre várias coisas. Acho que no geral o que defina a EMEF EJA com relação à militância não tem nenhum profissional que não fale dessa questão diferenciada. De você ter um aluno que ele é diferente do fundamental tradicional e ele estar aqui por ser, digamos, refugo das outras escolas, refugo do sistema e aqui nós tratamos esse refugo. E de que maneira? Aí entra a militância. Abraçando no sentido de entender, no sentido de avaliar, né? Porque a escola avalia se o aluno vai ser aprovado ou não. Então nós avaliamos, nós tiramos nossa roupagem tradicional da questão da avaliação para fazer uma avaliação pessoal, uma avaliação bem direcionada para aquele aluno (Educador 2).

Outra questão em torno da qual o paradigma militante, seus embates, contradições e afirmações, compareceu foi o aumento significativo do número de pessoas portadoras de necessidades especiais nas escolas de EJA. Face a esse aumento, como decidir o eixo das ações da escola? Se o norte das ações se pauta em: acolhimento às diferenças, incentivo à permanência dos estudantes, adequação dos trabalhos à concretude das realidades, como recusar matrículas? Se por um lado, não é simplesmente ignorar os pedidos de matrícula, pois fere claramente os princípios da escola, como negar que esse aumento reforça ainda mais a ideia de que a EJA tem se tornado um “depositário"? Ora, seriam necessárias ações que ultrapassassem a proposta do acolhimento, lutando para que as demais escolas também aceitassem estes estudantes. Não bastaria, assim, acolher novos estudantes em turmas já lotadas. É de igual urgência que seja pleiteado junto à Secretaria Municipal de Educação a abertura de novas turmas, com contratação de mais profissionais, e a criação de outras escolas diurnas de EJA para ampliar a oferta de ensino.

$\mathrm{Na}$ ocasião em que essa pauta de discussão foi apresentada aos professores, questionamos como a escola se entendia em meio a este movimento de "higienização" das escolas tradicionais e consequente transferência destes estudantes para a EJA. As respostas obtidas enunciaram certa insegurança por parte da escola, que ao passo que buscava agir junto ao Fórum de EJA para a abertura de novas turmas, via-se também no impedimento ético de negar matrícula a estes estudantes.

Em alguns espaços, por exemplo, é recorrente que associações de moradores e coordenadores de equipamentos públicos se posicionem contrários à permanência da escola nos espaços cedidos. Nesse sentido, a postura adotada pelos professores da EMEF EJA deixou explícito que assumir a militância (sic) naquela escola também significava se colocar na linha de enfrentamento com as instâncias educacionais superiores, com os gestores municipais, e até mesmo com a comunidade.

Eu acho que eu sou da militância da proteção. Eu acho que eu não preciso discursar sobre, mas eu preciso proteger meus alunos de uma determinada maneira. Quando você está dentro da sala de aula (eu fico pensando naquele menino que se suicidou aqui naquele bairro nobre)... Não foi exatamente o bullying que fez ele se suicidar, foi a 
falta de proteção. Você tem um monte professores que está vendo o cara sofrendo bullying e ninguém parou para conversar sobre, e ninguém parou para resolver a situação, e você não pode falar sobre isso na escola (Educador 3).

Nesta compreensão de militância existe um agravante, e assumir um lado apenas não era benquisto na dinâmica daquela equipe. Assim, as ações realizadas em prol de um grupo específico (negros, idosos, mulheres, jovens, população em situação de rua etc.) dentro da heterogeneidade do público da escola provocava o desvelamento de falas como "o que vocêfaz é ativismo e não militância" (sic). Diante disso, cabe compreendermos melhor o sentido atribuído às palavras militância e ativismo.

O termo militantia tem sua origem no latim e denotava o princípio de subserviência que rege a atividade do soldado militar. Schubert (2014) nos apresenta uma genealogia das militâncias com o intuito de discutir a organização dos coletivos e movimentos sociais no contemporâneo. Para isso, o autor parte da definição encontrada no Dicionário Aurélio, descrevendo-as como práticas carregadas de “acepções religiosas, políticas e militares" (SCHUBERT, 2014, p. 91). Ele percorre o histórico do militantismo, desde o surgimento da Ordem dos Cavaleiros Templários, passando pela Rússia leninista até chegar ao contemporâneo e nos apresenta análises sobre os efeitos que emergem a partir da apropriação e significação do termo ao longo dos tempos.

Vemos em Schubert (2014) que as relações estabelecidas entre as militâncias e as instituições religiosas, políticas e militares convergiam para o entendimento do militante como o sujeito que é considerado obstinado, dedicado a uma causa e que trabalha para defendê-la e propagar os ideais nela expressos. Em se tratando do viés político, a mobilização social é realizada como estratégia para difusão dos ideais coletivos, e por essa razão requer um conhecimento histórico das lutas e o envolvimento do sujeito em tempo integral. Por mais que os espaços de vivência sejam distintos esta é "a matéria política que orienta suas ações" (SOUZA, 2008, p. 118), o que nos indica que as ações de militância são indissociáveis da vida privada.

De origem alemã, aktivismus, o dicionário Aurélio (2016) traduz e define o vocábulo ativismo como uma "atitude moral que insiste mais nas necessidades da vida e da ação que nos princípios teóricos" ou a "propaganda ativa do serviço de uma doutrina ou ideologia". É considerado um posicionamento, um conjunto de "ações coletivas, politicamente orientadas, que demandam 'transgressão' e 'solidariedade' para a consecução de um objetivo comum” (BATISTA, 2012, p. 17). Comum que muitas vezes se direciona para uma compreensão identitária nas relações sociais. Condição que uniria os indivíduos pela semelhança - cultural, 
de gênero, política. Apesar dessas distinções no modo de condução das ações, não existe uma separação entre o ativismo e as outras militâncias. O ativismo é uma das manifestações da hibridação das expressões sociais, dos movimentos sociais tradicionais, da vanguarda etc. Em alguns momentos da história, principalmente em momentos de crise política e econômica, essas expressões se encontram e agem conjuntamente, mas sem perder seu caráter plural.

No século XIX o sujeito da militância tinha como característica principal essa dedicação integral à mobilização coletiva, atividade que ocorria nas ruas, nas praças, nas fábricas, nos cabarés e inclusive no ambiente doméstico. Na medida em que determinadas mudanças (econômicas e políticas) ocorreram na sociedade estas alcançaram também o sujeito da militância. A conquista de direitos sociais e trabalhistas não blindou esses sujeitos em favor de seu militantismo, e ainda que a carga horária, por exemplo, tenha sido reduzida ela passa a ser apenas uma parte da desgastante jornada de trabalho.

No Brasil, por exemplo, o retardo no processo de industrialização fez com que a Consolidação das Leis do Trabalho, de modo similar, ocorresse tardiamente - datada em 1943. Somente depois de duas ditaduras, que interromperam um breve período de governo democrático, é que uma Assembleia Constituinte foi convocada na intenção de sustentar uma democracia no país, fato que resultou da pressão civil e dos movimentos sociais. Conquistamos por determinação do Artigo $5^{\circ}$ inciso XVI da Constituição Federal o direito à livre manifestação, contanto que se mantenha a "ordem social".

\footnotetext{
Todos podem reunir-se pacificamente, sem armas, em locais abertos ao público, independentemente de autorização, desde que não frustrem outra reunião anteriormente convocada para o mesmo local, sendo apenas exigido prévio aviso à autoridade competente (BRASIL, 1988. GRIFOS NOSSOS).
}

Na coemergência do processo de industrialização e das leis trabalhistas, a própria ação militante tornou-se vinculada, no Brasil, ao Estado, no sentido de seu reconhecimento e legitimidade. Durante os anos 40, vai se delinear a noção de trabalhador e, consequentemente, de escolarização.

O processo de industrialização do país adentra o histórico de lutas pela Educação e a Educação de Jovens e Adultos, afinal foi por conta da necessidade de mão-de-obra qualificada para o mercado que os governos de 1940 a 1950 incentivaram a alfabetização maciça da população, bem como a criação de cursos profissionalizantes. Todavia, a Educação era destinada a determinadas parcelas da população e, por mais que o índice de analfabetismo tivesse diminuído, o acesso ao ensino médio e superior não foi garantido às populações periféricas e de baixa renda. 
Este intervalo temporal de negação do acesso e permanência à Educação, ressoante no Brasil na primeira década dos anos 2000, foi cenário para que a EMEF EJA, num desdobramento dos movimentos da Educação de Jovens e Adultos no Brasil, iniciasse sua história como um projeto de extensão universitária para alfabetização dos funcionários da Prefeitura Municipal de Vitória - e ainda atualmente recebe uma grande demanda de idosos que evadiram da escolarização [ou sequer os iniciaram] para trabalhar na construção civil e também nas lavouras no período da expansão industrial brasileira.

Outra característica marcante é uma compreensão binária sobre o militantismo que comparecia nos discursos dos docentes: ou se é militante e luta-se por tudo, ou se é ativista e limita-se a agir em prol de uma pauta específica. Tal leitura se evidenciava quando os professores decidiam sobre as equipes que ficariam responsáveis pela organização dos eventos (seminários) de caráter afirmativo na escola, por exemplo. Ao mesmo tempo em que se distribuía os organizadores dos seminários por afinidade, cobrava-se que fosse feita uma troca dessa estratégia para, assim, tensionar que outros sujeitos se envolvessem com pautas com as quais normalmente não se envolviam.

Analisamos que é preciso avaliar nesta escola como as próprias ações dos professores vêm reformulando um novo modo de militar na Educação de Jovens e Adultos. Lembremos, pois, que o militantismo sofreu transformações no modo de orientar suas ações, porém essas mesmas modulações não se deram de forma estanque. Detrás destes relevos, pistas ou vestígios, há muitas páginas da história que foram percorridas para que nos fosse possível afirmar a existência de uma escola de caráter militante atualmente. Da década de 1960, com a eclosão de golpes de Estado, que limitaram direitos civis e cassaram entidades e grupos de oposição aos governos, vimos fortalecer grupos militantes [guerrilheiros ou não] por toda América Latina: os movimentos sociais.

Lançando mão dos estudos da esquizoanálise, expusemos aos professores uma torção no pensamento sobre a luta de classes: a compreensão de que o Estado não opera apenas como macroestrutura localizada na figura dos governantes. De acordo com Deleuze e Guattari (2012), o fortalecimento do Capitalismo inaugurou uma nova forma de controle que ultrapassa a produção e o consumo de bens — trata-se do governo das subjetividades. A produção alcançou o processo de subjetivação, cuja matéria prima é o desejo, criando subjetividades capitalísticas (DELEUZE; GUATTARI, 2012). Os professores que vivenciaram a militância tradicional [a vanguarda] $]^{i}$ contrapunham a tal análise, afirmando que toda forma de captura empreendida pelo Capitalismo só existe em função da luta de classes. Outros professores replicaram alegando que 
se ainda existe luta de classes, hoje ela se mostra de forma sutil, porém, tão violenta quanto antes.

No bojo dos acontecimentos que compuseram o ano de 2016 no Brasil (ocupações estudantis devido ao sucateamento da Educação; escândalos de corrupção; golpe parlamentar; fortalecimento do pensamento conservador e outros atentados às mobilizações sociais) e uma vez que a opressão não está localizada apenas no acesso aos bens, mas sim no modo com as classes abastadas dominam modos de vida, deixamos à equipe da escola (e a nós mesmos) um questionamento: de que modo podemos transpor às capturas estatais para inventar um novo modo de militar? Como reassumir a frente de um campo de batalha cuja concretude das lutas se dá em vários planos? Se assim o fosse, estaríamos criando uma vanguarda?

\section{Considerações: entre sujeitos de militância e pessoalização de causas, um êthos militante}

As pistas encontradas no relevo da militância nos auxiliaram a analisar as relações da EMEF EJA com o militantismo na Educação de Jovens e Adultos. Ao compartilhar nossas análises acerca de uma militância que ultrapassou os muros da igreja e os exércitos medievais e adentrou os séculos da modernidade, buscamos elucidar que muitos dos elementos que compuseram a história do militantismo ganharam, ainda que em diferentes perspectivas, uma dimensão importante na vida de sujeitos que trabalhavam naquela escola.

Por meio desta pesquisa analisamos que as atribuições antagônicas dadas ao conceito de militância na educação poderiam ser lidas como um reflexo das práticas militantes no século passado e no início deste século; no entanto, é imprescindível demarcar que o militantismo também reverberava de maneira afirmativa na práxis docente naquela escola. Parte do trabalho que desenvolvemos nesta EMEF EJA preocupou-se em dar outro uso, para além das pautas macropolíticas, ao paradigma militante que nela é sustentado. Para nós, o modo como se produz conhecimento nessa escola mesmo em suas contradições, é um ensaio desejante da escola que estamos constantemente buscando construir.

\footnotetext{
Eu entrei em 2013 na EMEF EJA, de lá para cá eu observei que o que eu não fiz no regular eu acho que consegui fazer aqui. Na verdade, no regular, eu nem me propunha também. Comecei a ter essa atitude, de eu ver de outra forma depois que eu entrei na escola. Então eu já consegui ver alunos que entraram aqui, alunos que a gente achava que 'esse menino vai morrer' ou 'até ano que vem esse menino morre', e ver que esse menino agora está trabalhando, fazendo outra coisa, que o menino está no Ifes! (Educador 1)
} 
Analisamos a EMEF EJA como uma escola militante, cujo cotidiano está entremeado de conflitos e polêmicas, sem que, no entanto, isso impeça o estabelecimento de diálogo entre sua equipe para debate das ações pedagógicas. Ainda as vias pelas quais são conduzidas algumas das atividades escolares sejam atravessadas por práticas endurecidas, a aposta maior da equipe que compõe o corpo escolar é a de que o conhecimento produzido e adquirido em espaços como a escola deve ser, inicialmente, um vetor de transformação para a vida dos estudantes e demais envolvidos no processo de escolarização. É neste sentido que o paradigma presente na escola aponta para um modo de vida distinto, que desafia cotidianamente a não nos fixarmos em estigmas, mas sim a construir de forma coletiva uma vida ativa na perspectiva arendtiana (ARENDT, 2015).

Ativismo, intervenções urbanas, filiações partidárias, movimentos sociais, tudo isso parece bem distante da EMEF EJA - se colocado numa escala maior; todavia, o sujeito militante esteve presente na escola e vem conquistando suas próprias transformações. Assim, tanto a militância-vanguarda quanto o ativismo (ambos efeitos das transformações militantistas) compareciam no cotidiano da escola, sendo, por vezes, significados pela equipe de modo excludente.

Adequar sua rotina de trabalho aos princípios da escola pode não ser, a princípio, apreciado pelos docentes que chegam à EMEF, mas o que constatamos no período em que esta pesquisa foi realizada é que muitos destes professores têm construído um modo singular para acompanhar com sensibilidade a realidade dos estudantes, por exemplo. Para nós, isso também faz parte das transmutações sofridas pelo militantismo no século XXI.

Coisas que a gente pensa que eles precisam saber e coisas que eles podem utilizar na vida deles fora da escola. [...] Então eu to pensando no que eles vão fazer em casa, o que vai ser da saúde deles, como é que essa galera vai se alimentar... Eles vão sair para trabalhar, às vezes trabalham de noite. A gente tem aluno aqui que trabalha à noite, e o que é que eles podem fazer para ter uma qualidade de vida um pouquinho melhor? (Educador 1)

Para que a escola consiga manter, além do lugar que ocupa na rede pública de ensino, seu caráter transformador pela atividade docente é preciso que se compreenda que práticas como pessoalização e culpabilização são capturas tão eficazes quanto aquelas empreendidas, numa leitura marxista, pela aparelhagem estatal. Na medida em que o poder do Estado assume 
o controle político da vida criando capturas, outras formas de resistência urgem de emergir.

Afirmamos, deste modo, que quando a ação se estagna num modo único, então empobrecemos o paradigma da escola militante. Por este motivo, a militância que vislumbramos é construída cotidianamente, num plano ético, e que se constitui também em ações micropolíticas: um êthos docente militante.

\section{Referências}

ARDOINO, Jacques; LOURAU, René. As Pedagogias Institucionais. São Carlos: Rima, 2003.

ARENDT, Hannah. A condição humana. Roberto Raposo. (Tradução), 12a Edição. Rio de Janeiro: Forense Universitária, 2015.

ATIVISMO. In: HOLLANDA FERREIRA, A. B. Dicionário Online. Disponível em: $<$ https://dicionariodoaurelio.com/ativismo>. Acesso em: 17 set. 2016.

BATISTA, Jandré Corrêa. Apropriações ativistas em sites de redes sociais: cartografia das ações coletivas no twitter. Dissertação (Mestrado em Comunicação Social). Programa de PósGraduação em Comunicação Social. Pontifícia Universidade Católica do Rio Grande do Sul, RS, 2012.

BRASIL. Constituição da República Federativa do Brasil. Organização de Alexandre de Moraes. 16.ed. São Paulo: Atlas, 2000.

DELEUZE, Gilles; GUATTARI, Felix. 1874 - Três novelas ou o que se passou? In: G. Deleuze \& F. Guattari. Mil Platôs: Capitalismo e Esquizofrenia. (A. Guerra Neto e cols. Trads.). v.3, Rio de Janeiro: Editora 34, p. 58-75.

FOUCAULT, Michel. A coragem da verdade: o governo de si e dos outros II. Eduardo Brandão (Tradução); São Paulo. Martins Fontes, 2011.

KASTRUP, Virgínia. O funcionamento da atenção no trabalho do cartógrafo. In: PASSOS, E.;

KASTRUP, V.; ESCOSSIA, L. (Orgs.). Pistas do Método da Cartografia: pesquisaintervenção e produção de subjetividade. Porto Alegre: Sulina, 2012, p. 32-51.

LEMOS, Cássio Fernandes; OLIVEIRA, Andreia Machado. Mapeamento, Processo, Conexões: a cartografia como metodologia de pesquisa. Paralelo 31, v. 1, n. 8, 2017, p. 4051.

MACHADO, Jorge Alberto. Ativismo em rede e conexões identitárias: novas perspectivas para os movimentos sociais. In: Sociologias, Porto Alegre, ano 9, $\mathrm{n}^{\mathrm{o}} 18$, jul./dez. 2007, p. 248 285.

NEVES DA SILVA; Rosane. Ética e paradigmas: desafios da psicologia social contemporânea. In: PLONER, KS., et al., (org). Ética e paradigmas na psicologia social [online]. Rio de Janeiro: Centro Edelstein de Pesquisas Sociais, 2008. 313 p. ISBN: 978-8599662-85-4. Disponível em: <http://books.scielo.org/id/qfx4x>. Acesso em: 10/01/2017.

PASSOS, Eduardo; BARROS, Regina Benevides de. A cartografia como método de pesquisaintervenção. In: PASSOS, E.; KASTRUP, V.; ESCOSSIA, L. (Orgs.). Pistas do Método da 
Cartogradia: pesquisa-intervenção e produção de subjetividade. Porto Alegre: Sulina, 2012, p. 17-31.

SCHUBERT, Fernando Pinheiro. Práticas de militância nômade: experimentações rebeldes e novas estéticas de luta no contemporâneo. Dissertação (Mestrado em Psicologia Institucional). Programa de Pós-Graduação em Psicologia Institucional, Universidade Federal do Espírito Santo, ES, 2015.

SOUZA, Janice Tirelli P. Os jovens contemporâneos e a política contra o instituído. In: GROPPO, L. A.; FILHO, M. Z.; MACHADO, O. L. (Orgs). Movimentos juvenis da contemporaneidade. Recife: Universitária da UFPE, 2008, p. 117-156.

\footnotetext{
${ }^{\mathrm{i}}$ Vanguarda, do francês avant-garde, significa guarda avançada, o grupo que assume a frente da tropa no campo de batalha. Assim como militantia este é um termo militarizado, o que até certo ponto pode limitar a compreensão de luta e enfrentamento como ações exclusivamente vinculadas ao exército. Atualmente encontramos menções da vanguarda como sinônimo de inovação, de mobilizações que principiam o rompimento de alguns paradigmas, principalmente no que se refere ao campo das Humanidades.
} 